\title{
EFFECT OF SHORT-TERM STORAGE ON WALNUT FRUIT QUALITY
}

\author{
É. KónYAa*, G. BuJdosób,c, M. BERKI ${ }^{\mathrm{a}}$, M. NAGY-GASZTONYI and N. AdÁNYI ${ }^{\mathrm{a}}$ \\ ${ }^{a}$ Food Research Institute, National Agricultural and Innovation Centre, H-1022 Budapest, \\ Herman Ottó út 15. Hungary \\ ${ }^{b}$ Department of Pomology, Faculty of Horticultural Science, Corvinus University of Budapest, \\ H-1118 Budapest, Villányi út 29-43. Hungary \\ ${ }^{\mathrm{c}}$ National Agricultural Research and Innovation Centre Fruit Culture Research Institute, \\ H-1223 Budapest, Park utca 2. Hungary
}

(Received: 5 August 2014; accepted: 25 September 2014)

Two Hungarian and two introduced walnut cultivars were examined as fresh samples and under storage. Some important compositional data were determined in order to evaluate the differences between the cultivars and the changes after storage. The cultivars' oil contents were the same, but there was some difference in fatty acid composition; 'Alsószentiváni 117 ' had a higher mono-unsaturated fatty acid content than the others. Considering the oxidative stability, 'Alsószentiváni 117' contained good properties in all stages (induction time equals or higher than 10 h). Lower antioxidant capacity was measured in 'Chandler' samples compared to the others. 'Alsószentiváni 117' has higher $\alpha$ - and $\gamma$-tocopherol contents than the other cultivars studied. Two different drying methods were also compared in case of the Hungarian cultivars. The changes in compositional data showed no tendencies. We found that Hungarian cultivars were at least as valuable as the introduced ones.

Keywords: walnut, short-term storage, fatty acid composition, tocopherols, antioxidant capacity

The Persian walnut (Juglans regia L.) is harvested from early September till mid-October in Hungary. After the harvest, it is necessary to remove the husk, wash, dry, size and pack the fruits or crack and pack the kernels. The peak selling period of this fruit crop is in November or during Advent, therefore a short storage is needed for the prepared walnut. The Hungarian bred walnut cultivars have good compositional value (BuJdosó et al., 2010, 2014) as published before. Our aim is to save the good fruit quality (light shell and kernel colour, good taste) and the good compositional value of the dried in-shell walnut. There is no protocol for walnut storage in Hungary; the growers mainly keep the fruit between 2 and $10^{\circ} \mathrm{C}$ in a dark room.

There are only a few papers on walnut storage. One study gives results on this topic, but focuses on evaluating the effect of low temperature $\left(10^{\circ} \mathrm{C}\right)$ on walnut fruit damage and reinfestation before shipping from California to avoid insect infections (JoHnson et al., 2010). Whole walnut storage at $10{ }^{\circ} \mathrm{C}$ and relative humidity conditions of $60 \%$ gave the best results in order to save the original fruit quality (Lopez et al., 1995). Another research study stated that storage at $1{ }^{\circ} \mathrm{C}$ had a positive effect on saving total phenol compound content, total antioxidant content, and colour of the cultivars stored for 12 months compared to samples stored at $20^{\circ} \mathrm{C}$ (Christopoulos \& TsAnTILI, 2011). It has been found that tocopherol content of 'Franquette' and 'Hartley' stored at $4{ }^{\circ} \mathrm{C}$ decreased by $30 \%$ after less than 3 months (LAVEDRINE et al., 1997).

\footnotetext{
* To whom correspondence should be addressed.

Phone: +36-1-796 0407; fax: +36-1-796 0449; e-mail: e.konya@cfri.hu
} 
According to some results, there is a positive correlation between the peroxide and lipoxigenase content of cultivars and their storability (Österberg et al., 2001; KosÁRY et al., 2009). According to Österberg and co-workers (2001), 'Rex' and 'Vina' had the highest peroxidase content after three years storage among the examined cultivars, the 'Geisenheim 120 ' and 'Stanley' produced the lowest.

There is no ethylene production during the storage. Drying at $36{ }^{\circ} \mathrm{C}$ for 24 hours decreased the total phenol (TP) content as compared to fresh walnuts. TP and the total antioxidant capacity showed a 1.2- to 1.3-fold increase in the fresh kernels after the first 20 days of storage at $1{ }^{\circ} \mathrm{C}$, and remained stable during the next 20 days. There was no growth in total phenol compounds (vanillic acid, protocatechuic acid, ellagic acid) at $8{ }^{\circ} \mathrm{C}$, but an increasing tendency was observed at $1{ }^{\circ} \mathrm{C}$ (Miltiadis et al., 2012).

The aim of this paper is to study the effect of drying and low temperature storage on some Hungarian and introduced bred cultivars' fruit, as well as determination of oxidative stability and components of walnuts affecting rancidity (water content, antioxidant capacity, tocopherol content, fatty acid composition).

\section{Materials and methods}

\subsection{Samples studied}

Cultivars 'Milotai 10', 'Alsószentiváni 117', 'Chandler', and 'Franquette' were investigated. The fruit samples were taken from Juglans Hungaria Ltd.'s walnut orchard located in Lengyeltóti (Hungary) at optimal ripening time. The optimal ripening time means, when 50\% of husks are open ( $\mathrm{FS}=$ fresh samples). After harvest the husk was eliminated by hand and the fruit were washed and dried to $10 \%$ moisture content in the dryer machines at 35 to $37{ }^{\circ} \mathrm{C}$ air temperature during 36 or $48 \mathrm{~h}$, depending on the samples' moisture content. The samples were not bleached during the preparation process. After drying, half of the samples were examined in the lab (DS=dried samples), the other half was stored as dried in shell walnut at $8{ }^{\circ} \mathrm{C}$ for two months. After the storage, in December, the samples were measured again ( $\mathrm{SS}=$ stored samples), because this is the most important walnut selling period of the year.

In case of 'Milotai 10' and 'Alsószentiváni 117' two ways of drying were applied. The warm method written above and the cold method, which means air-dried samples (ADS=airdried samples).

\subsection{Determination of water content}

Determination of water content was carried out at $103{ }^{\circ} \mathrm{C}\left( \pm 2{ }^{\circ} \mathrm{C}\right)$ for $6 \mathrm{~h}$ at atmospheric pressure according to ISO (2000).

\subsection{Determination of oil content}

Oil content was extracted with petroleum ether and the solvent was removed in rotary vacuum evaporator according to Hungarian STANDARD (2000).

\subsection{Determination of fatty acid composition}

Fatty acids were analysed from the extracted oil by gas chromatography (Agilent 7890A GC System, Agilent Technologies, Santa Clara, CA, United States) of methyl esters of fatty acids 
(Tóth-Markus \& SAss-Kiss, 1993). Column was Supelco SP-2560 $100 \mathrm{~m} \times 0.25 \mathrm{~mm}, 0.2 \mu \mathrm{m}$ film thickness (Supelco, Bellefonte, PA, United States). Oven temperature program: $140{ }^{\circ} \mathrm{C} 5 \mathrm{~min}, 4^{\circ} \mathrm{C} \mathrm{min}{ }^{-1}$ until $240{ }^{\circ} \mathrm{C}, 10 \mathrm{~min}$ on final temperature; injector temperature $220{ }^{\circ} \mathrm{C}$, detector temperature $250{ }^{\circ} \mathrm{C}$; carrier gas: hydrogen, column flow $1 \mathrm{ml} \mathrm{min}{ }^{-1}$; automatic injection, injected amount $1 \mu$ l. Oils were stored in deep freezer for a very short time until analysis.

\subsection{Determination of oxidative stability}

The oxidative stability of the freshly extracted oil was measured by Rancimat method (Rancimat 743, Metrohm, Herisau, Switzerland). With the Rancimat method, the sample is exposed to an air flow at a constant temperature between 50 and $220{ }^{\circ} \mathrm{C}\left(100{ }^{\circ} \mathrm{C}\right.$ in our case $)$. Highly volatile, secondary oxidation products (especially formic acid) are transferred into the measuring vessel with the air flow, where they are absorbed in the measuring solution (distilled water). Here the conductivity is continuously registered. The organic acids can thus be detected by increasing the conductivity. The time until occurrence of these secondary reaction products is referred to as the induction time $(\mathrm{h})$ or induction period, which is a good indicator for the oxidation stability (RANCIMAT, 2009).

\subsection{Determination of antioxidant capacity}

Samples were extracted by methanol, stored at $4{ }^{\circ} \mathrm{C}$ for $24 \mathrm{~h}$, and filtered after $30 \mathrm{~min}$ shaking. The colour reaction was carried out with 2,2-diphenyl-1-pycrylhydrazyl (DPPH) at $36{ }^{\circ} \mathrm{C}$ for $30 \mathrm{~min}$ in dark, and the absorbance decrease against blank sample was measured at $517 \mathrm{~nm}$ (ATI Unicam UV-Vis Spectrometer UV2, Unicam, England). The antioxidant capacity was given in Trolox equivalent per $100 \mathrm{~g}$ dry matter (TE/100 g d.m.) (BRAND-WiLliams et al., 1995).

\subsection{Determination of tocopherols}

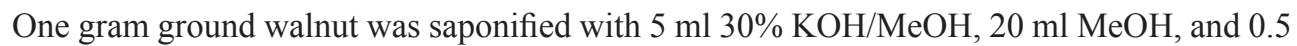
$\mathrm{g}$ ascorbic acid added, and boiled for $35 \mathrm{~min}$ on a sand bath. After cooling, $15 \mathrm{ml}$ water containing $20 \%$ sodium chloride and $40 \mathrm{ml}$ of $n$-hexane were added to sample. Tocopherols were separated in upper phase after a short shaking with a separating funnel. Another $40 \mathrm{ml}$ of hexane was added to the lower phase and the separation was repeated. The lower phase was removed and the two upper phases were united in a separating funnel, washed twice with distilled water, and filtered through dry sodium sulphate. The filtrate was evaporated in rotadest and re-dissolved in $10 \mathrm{ml}$ of HPLC grade hexane (SPEEK et al., 1985).

The HPLC system consisted of Shimadzu RF-535 Fluorescence HPLC Monitor Detector (Shimadzu, Kyoto, Japan), 250×4.6 mm, $5 \mu \mathrm{m}$, Nucleosil 100 Silica column (MachereyNagel, Düren, Germany). The eluent was $n$-hexane-abs. ethanol, 99.6:0.4 and the flow rate

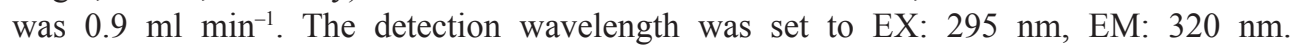
$\alpha$-tocopherol was used to identify the peaks.

\subsection{Chemicals}

All the chemicals were of analytical grade (VWR International LLC., Radnor, PA, United States), except for tocopherols, where HPLC grade chemicals were used (VWR International LLC., Radnor, PA, United States). 


\subsection{Statistical analysis}

All analyses were carried out in triplicate. Data are given as mean \pm standard deviation and were analysed by $t$-test in Excel.

\section{Results and discussion}

'Alsószentiváni 117' and 'Milotai 10', the two main walnut cultivars in Hungary, were compared to two introduced cultivars, 'Chandler' and 'Franquette'. Compositional data determined from walnut samples are summarised in Tables 1 and 2.

The oil content is the lowest in fresh samples of all the cultivars. At this stage, the oil content of 'Chandler' was lower than of the others. The results show significant difference between the two ways of drying for the Hungarian cultivars $(\mathrm{P}<0.05)$.

The cultivars have a rather similar fatty acid composition. The difference between Hungarian cultivars and 'Chandler' and 'Franquette' was seen in the unsaturated fatty acids. 'Alsószentiváni 117 ' has lower PUFA (PUFA=polyunsaturated fatty acid) content, but its MUFA (MUFA=monounsaturated fatty acid) content is higher proportionally. The MUFA value (oleic acid, C18:1 content) is slightly lower in 'Chandler', but the PUFA content is higher than in the other cultivars. The difference in PUFA is caused by the higher $\alpha$-linolenic acid (C18:3) content in 'Chandler, which makes it more sensitive to oxidation'. To compare the two drying methods, there was no difference between them.

Induction time, characterising the oxidative stability of oil extracted from walnut samples, differs for each sample. For cultivar 'Alsószentiváni 117', the induction time was increasing after drying and under storage. Comparing the two drying methods we found that air-dried samples showed rancidity $3 \mathrm{~h}$ later than the samples dried with warm air. For cultivar 'Milotai 10', the induction time of dried sample was higher than the fresh sample's, and decreased in the stored samples. The cultivar 'Chandler' was most inclined to rancidity. The induction time of dried sample of 'Chandler' was the lowest value of all the cultivars. Fresh sample of 'Franquette' had also low induction time $(4.19 \mathrm{~h})$, and there was no difference between dried and stored samples in oxidative stability for 'Franquette'. According to VIDRIH and co-workers (2010), the correlation of oils' induction time and the PUFA content is negative, so the growth of induction time is caused by the decrease of linoleic and linolenic acids. Our results show the same tendency. In the induction time results we found significant difference between the two drying methods $(\mathrm{P}<0.05)$.

According to antioxidant capacity analysis, 'Chandler' had lower free radical scavenging ability than the other cultivars. Its fresh sample's antioxidant capacity was about third of the others and in the other two stages the values were lower than that of other samples. This can contribute to its lower oxidative stability. There is some tendency in the change of antioxidant capacity of samples. In case of 'Alsószentiváni 117', 'Milotai 10' air-dried, 'Chandler', and 'Franquette' the antioxidant capacity of dried samples is above the other stages, and under storage, all of the cultivars lose from their antioxidant capacity. Comparing the two ways of drying, in case of 'Alsószentiváni 117' there is no difference in antioxidant capacity, but for 'Milotai 10' the air dried samples (stored as well) have about $20 \%$ higher antioxidant capacity than the samples dried by warm air. 
KÓNYA et al.: SHORT-TERM STORAGE OF WALNUT

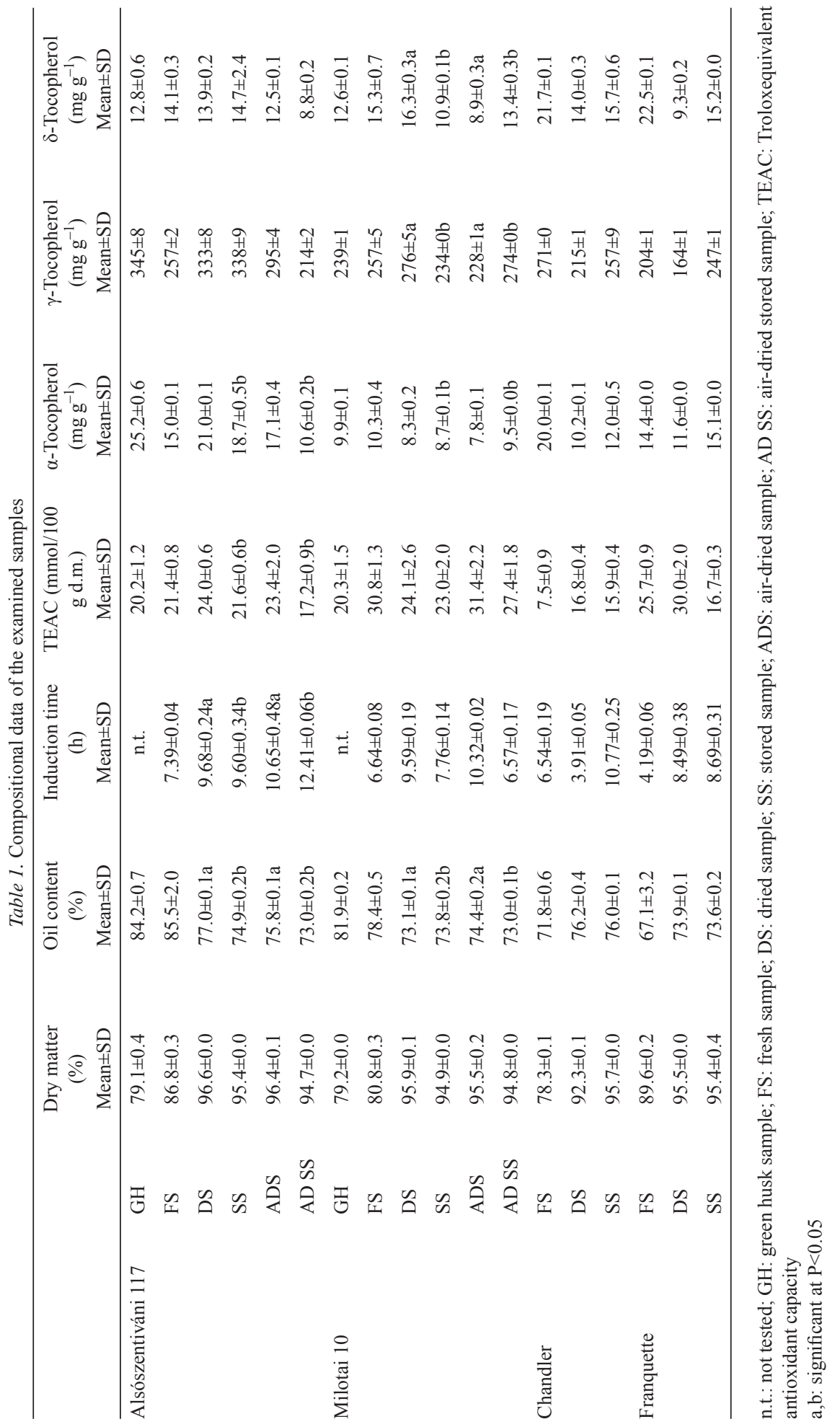




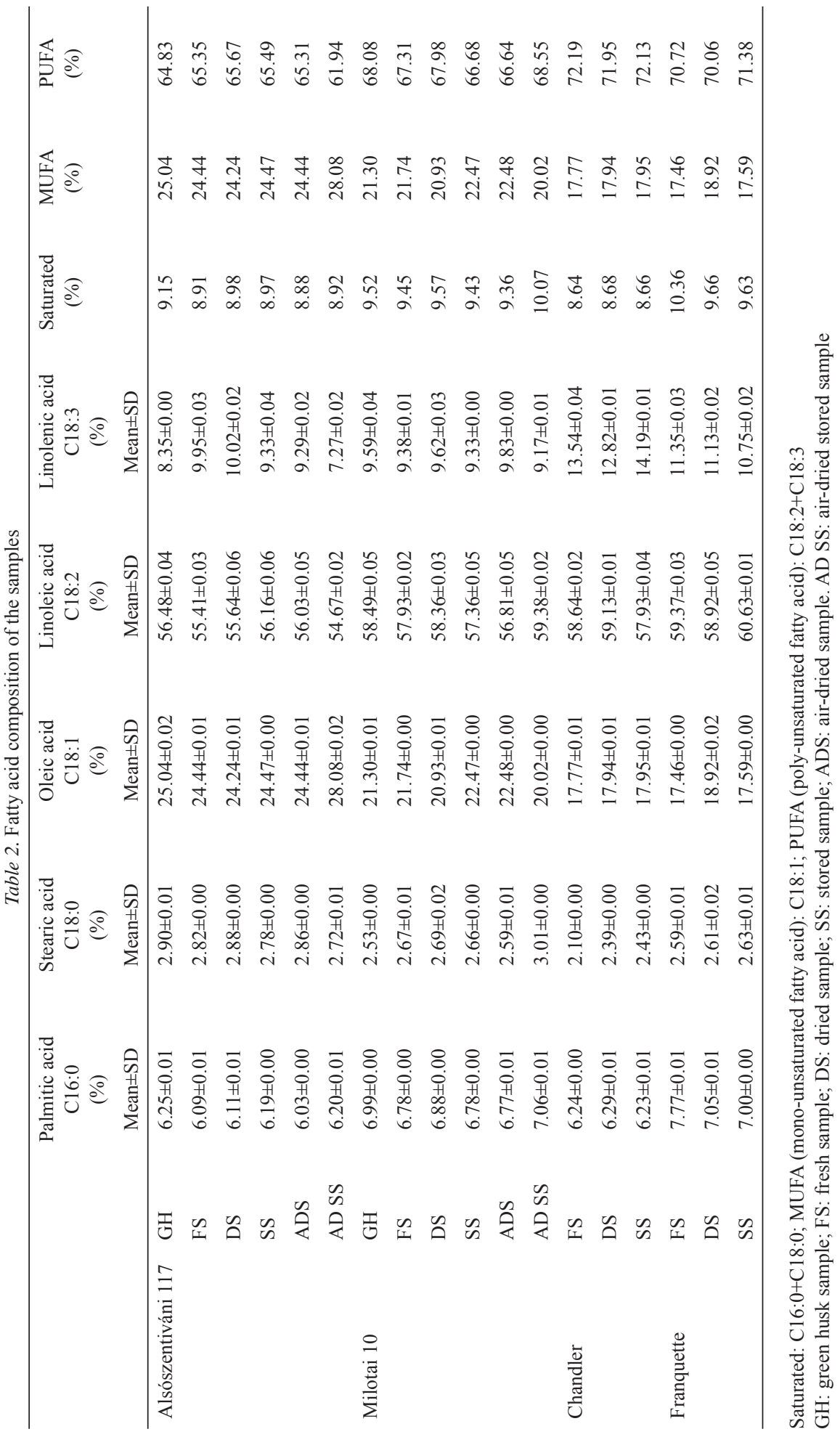


Three tocopherol isomers were analysed: $\alpha$-, $\delta$-, and $\gamma$-tocopherols. The $\gamma$-tocopherol content is an order of magnitude higher than the $\alpha$ - and $\delta$-tocopherol contents of the samples. 'Alsószentiváni 117's $\gamma$-tocopherol content is above the other cultivars in all stages, except in air-dried stored sample, because under storage this sample's $\gamma$-tocopherol content decreased to its two-third. Only 'Chandler' fresh samples have $\alpha$-tocopherol content in the same level as 'Alsószentiváni 117'.

The $\alpha$-tocopherol content of the other main Hungarian cultivar, 'Milotai 10', was about half of the $\alpha$-tocopherol of the 'Alsószentiváni 117'. Under drying the $\alpha$-tocopherol content of 'Chandler' decreased to half of the fresh sample and slightly increased under storage. For 'Milotai 10' there was no difference between the two drying methods, for 'Alsószentiváni $117^{\prime}$ the warm air dried samples showed higher $\alpha$-tocopherol content than the air dried samples, but there was no significant difference. The $\alpha$-tocopherol content of the latter decreased by about half under storage.

There are larger differences in $\delta$-tocopherol content between the drying stages and the cultivars. The 'Chandler' and 'Franquette' fresh samples are prominent, but their $\delta$-tocopherol content decreased to around $70 \%$ under drying and storage. In the change of the $\delta$-tocopherol content of 'Alsószentiváni 117' and 'Milotai 10' no such tendency was observed.

\section{Conclusions}

In our research the main two Hungarian and two foreign cultivars 'Chandler' and 'Franquette' were tested. The samples were examined in different stages (fresh, dried, stored) and some compositional data are presented. According to our data, the composition of traditional Hungarian cultivars is as valuable as or better than the foreign ones. The Hungarian cultivars have better position in global market because of their earlier harvest time.

We examined two kinds of drying method for the Hungarian cultivars, and according to the results, differences can be found in the parameters tested between these methods. Summarizing all the results there is no tendency in the effect of the drying methods.

\section{References}

Brand-Williams, W., Cuvelier, M.E. \& Berset, C. (1995): Use of free radical method to evaluate antioxidant activity. LWT - Food Sci. Technol., 28, 25-30.

Bujdosó, G., Tóth-Markus, M., Daood, H.G., AdÁnyi, N. \& Szentiványi, P. (2010): Fruit quality and composition of Hungarian bred walnut cultivars. Acta Alimentaria, 39, 35-47.

Bujdosó, G., Végvári, Gy., Hajnal, V., Ficzek, G. \& Tóth, M. (2014): Phenolic profile of the kernel of selected Persian walnut (Juglans regia L.) cultivars. Not. Bot. Horti. Agrobo., 42(1), 24-29.

Christopoulos, M.V. \& Tsantili, E. (2011): Effects of temperature and packaging atmosphere on total antioxidants and colour of walnut (Juglans regia L.) kernels during storage. Sci. Hortic., 131, 49-57.

Hungarian Standard (2000): Olajmagdarák. Az olajtartalom meghatározása. 1. rész: Hexános (vagy petroléteres) extrakciós módszer. (Oilseed residues. Determination of oil content. Part 1: Extraction method with hexane (or light petroleum)). MSZ EN ISO 734-1:2000

ISO (2000): Oilseeds -Determination of moisture and volatile matter content. ISO 665-200

Johnson, J.A., Mitcham, E.J., Monzon, M., Tang, J. \& Wang, S. (2010): Methyl bromide alternatives for postharvest insect disinfestations of California walnuts. Acta Hortic., 861, 383-388.

Kosáry, J., Bujdosó, G., Szentiványi, P., Rehus, D., Emmert, M. \& Farkas, Cs. (2009): A lipoxigenázok változásai a növényekben. 10. Különbözö diófajták (Juglans regia L.) avasodási hajlamának vizsgálata biokémiai 
módszerekkel. (Changes of lipoxigenase in the plants. 10. Examination of different walnut cultivars' (Juglans regia L.) rancidification using biochemical methods). Olaj, Szappan, Kozmetika., 58, 77-80.

Lavedrine, F., Ravel, A., Poupard, A. \& Alary, J. (1997): Effect of geographic origin, variety and storage on tocopherol concentrations in walnuts by HPLC. Food Chem., 58, 135-140.

Lopez, A., Pique, M.T., Romero, A. \& Aleta, N. (1995): Influence of cold-storage conditions on the quality of unshelled walnuts. Int. J. Refrig., 18, 544-549.

Miltiadis, V., Christopoulos, M.V. \& Tsantili, E. (2012): Storage of fresh walnuts (Juglans regia L.) - Low temperature and phenolic compounds. Postharvest Biol. Tec., 73, 80-88.

Österberg, K., Savage, G.P. \& McNeil, D.L. (2001): Oxidative stability of walnuts during long term in shell storage. Acta Hortic., 544, 591-597.

Rancimat (2009): 743 Manual, Metrohm Ltd., Herisau, Switzerland.

Speek, A.J., Schrijver, J. \& Schreurs, W. (1985): Vitamin E composition of some seed oils as determined by highperformance liquid chromatography with fluorometric detection. J. Food Sci., 50, 121-124.

Tóth-Markus, M. \& Sass-Kiss, Á. (1993): Effect of cooking on the fatty acid composition of silver carp (Hypophtalmichtis molitrix, V.). Acta Alimentaria, 22, 25-35.

Vidrih, B., Vidakovič, S. \& Abramovič, H. (2010): Biochemical parameters and oxidative resistance to thermal treatment of refined and unrefined vegetable edible oils. Czech J. Food Sci., 28, 376-384. 